\title{
Functionalization of lambda-zirconium phosphate with ethylenediaminetetraacetic acid: Synthesis, characterization and applications
}

\author{
HUSSEIN ALHENDAWI ${ }^{\mathrm{a}, *}$, ERNESTO BRUNET ${ }^{\mathrm{b}}$, OLGA JUANES $^{\mathrm{b}}$, SALEM IDHAIR $^{\mathrm{a}}$, \\ HUDA HAMMOUDA ${ }^{\mathrm{a}}$, ELENA RODRÍGUEZ PAYÁN ${ }^{\mathrm{b}}$ and \\ MARÍA DE VICTORIA RODRÍGUEZ \\ ${ }^{a}$ Department of Chemistry, Faculty of Science, Al-Azhar University of Gaza, 1277 Gaza, Palestine \\ ${ }^{\text {b}}$ Departamento de Química Orgánica, Facultad de Ciencias C-I-602, Universidad Autónoma de Madrid, \\ 28049 Madrid, Spain \\ e-mail: hussein.alhendawi@yahoo.com
}

MS received 12 March 2014; revised 26 April 2014; accepted 6 May 2014

\begin{abstract}
A new layered organic-inorganic material based on $\lambda$-Zirconium phosphate $(\lambda-\mathrm{ZrP})$ and ethylenediaminetetraacetic acid $\left(\mathrm{H}_{4} \mathrm{Y}\right)$ has been prepared. The thermal analyses, $\mathrm{X}$-ray diffractometry and FT-IR spectrophotometry confirm the introduction of $\mathrm{H}_{4} \mathrm{Y}$ inside the interlayer gallery of $\lambda$-ZrP. The pristine $\lambda$-ZrP and its new polyaminocarboxylic acid functionalized derivative $\left(\lambda-\mathrm{ZrPH}_{2} \mathrm{Y}\right)$ exhibit high potential for the application in the area of hard water treatment, where their $\mathrm{Ca}^{2+}$ uptake capacities are found to be 32.0 and $40.4 \mathrm{mg} \mathrm{Ca}{ }^{2+}$ per gram of $\lambda$-solid, respectively.
\end{abstract}

Keywords. $\lambda$-Zirconium phosphate; ethylenediaminetetraacetic acid; functionalized $\lambda$-ZrP; layered inorganic-organic materials; metal ion uptake.

\section{Introduction}

Ethylenediaminetetraacetic acid (EDTA) (figure 1) is a mutidentate complexing agent, which can bind metal ions through multiple atoms. Therefore, it can wrap itself around metal ions like a claw.

EDTA is commonly added to food packaging in order to complex metal ions that catalyze reactions that can cause food spoilage and rancidity, discoloration, offflavour or odour. It has also many other applications in medicine (treatment for lead and heavy metals poisoning), agriculture, polymerization, pulp and paper applications and textiles.

It is well-known that one of the methods used to determine the total hardness of water, caused mainly by the presence of $\mathrm{Mg}^{2+}$ and $\mathrm{Ca}^{2+}$, is complexometric titration with EDTA. Accordingly, immobilization of EDTA inside the framework of the inorganic supports is expected to produce porous materials able to efficiently entrap those metal ions that cause water hardness.

It is noteworthy that the superficial chloride ligand of $\lambda$-zirconium phosphate $(\lambda-\mathrm{ZrP}), \lambda$ - $\mathrm{ZrPO}_{4} \mathrm{Cl}\left(\mathrm{CH}_{3}\right)_{2} \mathrm{SO}$, can be topotactically exchanged by carboxylic acid compounds. $^{1,2}$ Therefore, ethylenediaminetetraacetic

\footnotetext{
*For correspondence
}

acid (EDTA) can be immobilized inside the interlayer of $\lambda$ - ZrP through the above mentioned exchange.

Basically, $\lambda-\mathrm{ZrP}$ is structurally related to $\gamma-\mathrm{ZrP}$ (figure 2), which can be formed by bridging four different zirconium atoms with $\left(\mathrm{PO}_{4}\right)$ in a similar manner to that of $\gamma$-ZrP, then balancing the residual positive charge and completing the octahedral configuration of each zirconium atom with a monovalent anionic monodentate ligand (flouride or chloride) and neutral monodentate ligand (dimethyl sulfoxides). ${ }^{3-6}$ The building blocks formation of this lamellar structure is shown in figure 2 .

There are very few examples in the literature about the construction of porous organic- and inorganicinorganic materials based on $\lambda-\mathrm{ZrP}$ with tailor-made properties. $^{2,7,8}$

This study aims to immobilize EDTA inside the interlayer gallery of $\lambda-\mathrm{ZrP}$ in order to obtain organicinorganic framework with potential applications in the area of hard water treatment.

\section{Experimental}

All chemicals and reagents used were of analytical grade. All of them were purchased from Aldrich Co., and used as supplied. $\lambda$-Zirconium phosphate was 


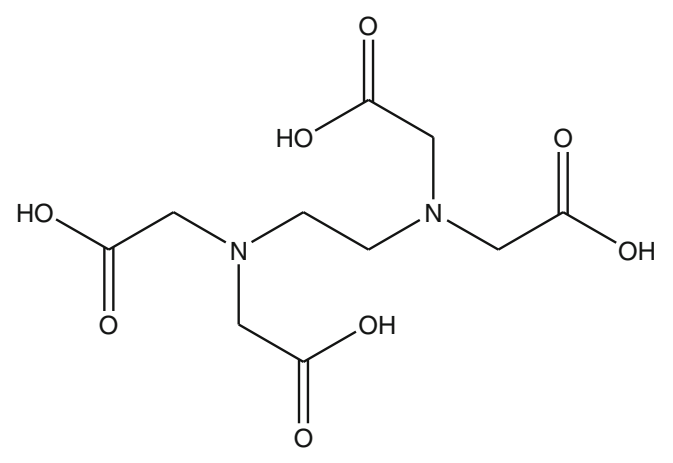

Figure 1. Structure of EDTA $\left(\mathrm{H}_{4} \mathrm{Y}\right)$.

prepared using a literature described procedure (interlayer distance $1.02 \mathrm{~nm}){ }^{8}$

\subsection{Topotactic exchange of EDTA with $\lambda-Z r P$}

A $1.84 \mathrm{~g}$ amount of $\mathrm{ZrPO}_{4} \mathrm{Cl}(\mathrm{dmso})$ was contacted with $229 \mathrm{~mL}$ of a $6.73 \times 10^{-3} M \mathrm{H}_{4}$ EDTA and 6.73 $\times 10^{-3} M \mathrm{Na}_{4}$ EDTA solution using a $33.4 \%$ (v/v) $\mathrm{dmso} /$ water mixture as solvent. The mixture was heated at $75^{\circ} \mathrm{C}$ for one week. The resulting white solid was separated by centrifugation and washed with $33.4 \%$ $(\mathrm{v} / \mathrm{v}) \mathrm{dmso} / \mathrm{water}$ solution $(3 \times 100 \mathrm{~mL})$. Finally it was dried at $80^{\circ} \mathrm{C}$ for $24 \mathrm{~h}$ to obtain $1.14 \mathrm{~g}$ of the product which was stored over $\mathrm{P}_{2} \mathrm{O}_{5}$.

\subsection{Hard water treatment: $\mathrm{Ca}^{2+}$ uptake}

A $250 \mathrm{mg}$ of $\lambda$-solid $\left(\lambda-\mathrm{ZrP}\right.$ or $\left.\lambda-\mathrm{ZrPH}_{2} \mathrm{Y}\right)$ was shaken with $12.5 \mathrm{~mL}$ of tap water, previously diluted to $25 \mathrm{~mL}$ with distilled water and adjusted to $\mathrm{pH} 10$ by adding $2.5 \mathrm{~mL}$ of $\mathrm{NH}_{3} / \mathrm{NH}_{3} \mathrm{Cl}$ buffer solution using a polyethylene bottle with a good stopper. Several metal uptake reactions were carried out at different time intervals $(0.5-72 \mathrm{~h})$. The metal ion concentration was measured by flame photometer after separation of the insoluble solid by centrifuge and diluting the supernatant solution to the linear range of the calibration curve for $\mathrm{Ca}^{2+}$. Each measurement was performed three times.
The metal ion uptake is calculated as $\mathrm{mg}$ of $\mathrm{Ca}^{2+} / \mathrm{g}$ of $\lambda$-solid.

\subsection{Characterization}

$\mathrm{X}$-ray powder diffraction (XRD) patterns were recorded at room temperature on Siemens D-5000 diffractometers with $\mathrm{Cu} K \alpha$ radiation $(\lambda=0.154 \mathrm{~nm})$ and Ni filter at $40 \mathrm{kV}, 30 \mathrm{~mA}$, a scanning rate of $5^{\circ} \mathrm{min}^{-1}$, and a $2 \theta$ angle ranging from $3^{\circ}-70^{\circ}$. Infrared spectra were recorded on a FTIR-8201PC spectrometer using $\mathrm{KBr}$ disk in the range $4000-400 \mathrm{~cm}^{-1}$. Elemental analyses were performed on a Perkin Elmer II $2400 \mathrm{CHN}$ analyzer. Thermogravimetric analyses was performed on a Mettler-Toledo TGA/STDA 851e apparatus and recorded at $5^{\circ} \mathrm{C} / \mathrm{min}$. The $\mathrm{Ca}^{2+}$ concentration in tap water samples was measured on a Flame photometer ANA-135. Structure modelling was carried out on PC computers using the Hyperchem release 7 and the molecular mechanics method $\mathrm{MM}+$.

\section{Results and Discussion}

The ligand exchange reaction between $\lambda-\mathrm{ZrP}$ and EDTA $\left(\mathrm{H}_{4} \mathrm{Y}\right)$ is expected to take place in a topotactic manner, i.e., it occurs without affecting the integrity and rigidity of the inorganic layers.

The new functionalized $\lambda-\mathrm{ZrP}$ is prepared by postsynthesis modification of the surface of inorganic layers of $\lambda-\mathrm{ZrP}$, where $\lambda-\mathrm{ZrP}$ is contacted with $\mathrm{H}_{4} \mathrm{Y} / \mathrm{Na}_{4} \mathrm{Y}$ equimolar mixture using a $33.4 \%(\mathrm{v} / \mathrm{v}) \mathrm{dmso} /$ water mixture as solvent (see section 2). The resulting solid phase material designated as $\lambda-\mathrm{ZrPH}_{2} \mathrm{Y}$ with $\mathrm{C}, \mathrm{H}$, $\mathrm{N}, \mathrm{S} \%$ content of $20.60,3.25,3.40,7.77$ (calculated: $20.53,3.20,3.42,7.83$ ), respectively. This elemental analysis is in agreement with the formula: $\mathrm{ZrPO}_{4}\left(\mathrm{C}_{10} \mathrm{H}_{14} \mathrm{~N}_{2} \mathrm{O}_{8}\right)_{0.5}\left(\mathrm{CH}_{3}\right)_{2} \mathrm{SO}$.

It is important to mention that chloride was not observed by elemental analysis, which means that the chloride anions of $\lambda$-ZrP are complete exchanged by those of carboylate groups of EDTA.

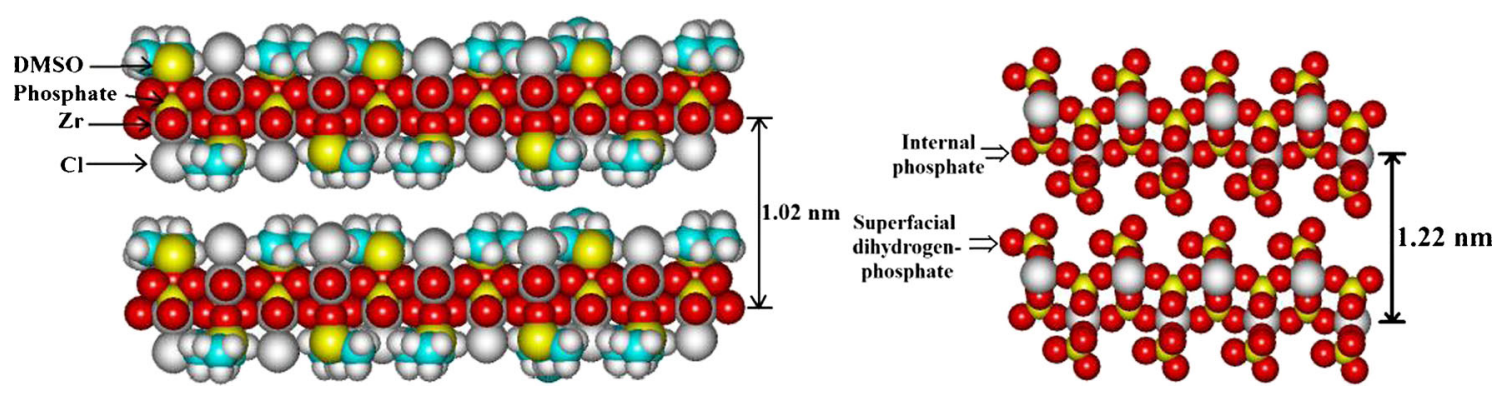

Figure 2. Space-filling models (Zr, gray; $\mathrm{P}$, yellow; O, red; H, white) of two consecutive layers of $\lambda-\mathrm{ZrP}$ (left) and $\gamma$-ZrP (right). The experimental interlayer distances are shown. 
Figure 3 shows the thermogravimetric analysis (TGA) of $\lambda-\mathrm{ZrPH}_{2} \mathrm{Y}$. There are two distinguishable weight loss intervals. The first one $\left(200-375^{\circ} \mathrm{C}\right)$ is

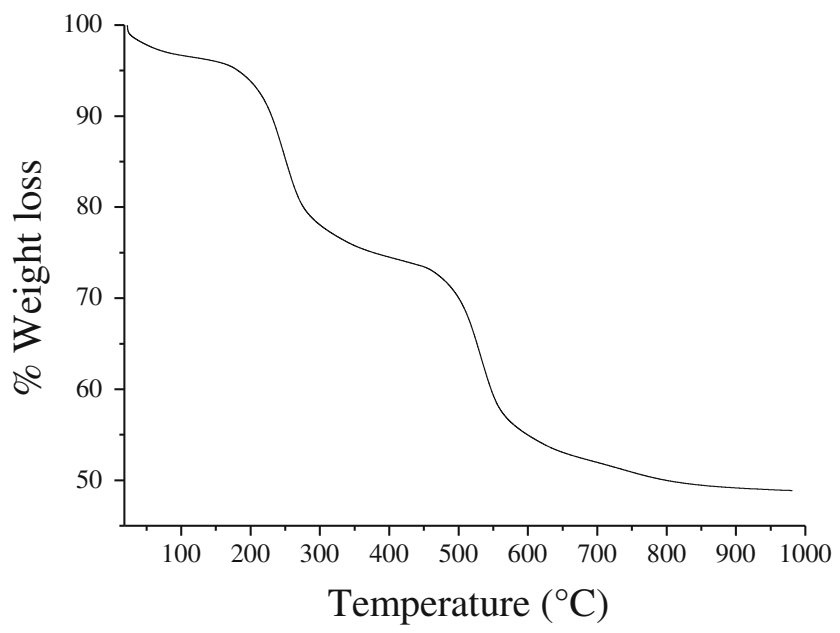

Figure 3. TGA curve of $\lambda-\mathrm{ZrPH}_{2} \mathrm{Y}$ obtained at a heating rate $5^{\circ} \mathrm{C} / \mathrm{min}$.

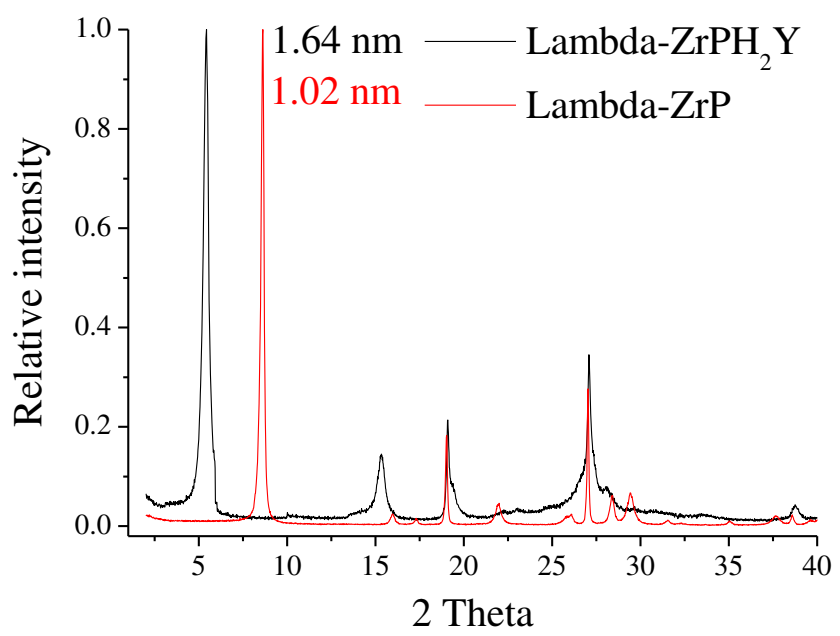

Figure 4. $\mathrm{X}$-ray powder diffraction patterns of $\lambda-\mathrm{ZrP}$ and $\lambda$-ZrPY. attributed to the loss of dmso. The second weight loss interval $\left(375-600^{\circ} \mathrm{C}\right)$ corresponds to volatilization of EDTA moiety. The total weight loss percent at $1000^{\circ} \mathrm{C}$ $(51.11 \%)$ is in good agreement with the calculated one $(52.57 \%)$. The later percentage is calculated according the following thermal decomposition scheme.

$$
\begin{aligned}
& \mathrm{ZrPO}_{4}\left(\mathrm{C}_{10} \mathrm{H}_{14} \mathrm{~N}_{2} \mathrm{O}_{8}\right)_{0.5}\left(\mathrm{CH}_{3}\right)_{2} \mathrm{SO} \\
& \quad+\mathrm{n} \mathrm{O}_{2} \rightarrow \mathrm{ZrOO}_{4}\left(\mathrm{C}_{10} \mathrm{H}_{14} \mathrm{~N}_{2} \mathrm{O}_{8}\right)_{0.5} \\
& \quad+\text { gaseous products } \rightarrow 1 / 2 \mathrm{ZrO}_{2} \\
& \quad+1 / 2 \mathrm{ZrP}_{2} \mathrm{O}_{7}+\text { gaseous products }
\end{aligned}
$$

To sum up, the thermal decomposition data collected from elemental analysis and TGA are in accordance and compatible with the calculated chemical formula mentioned above $\left(\mathrm{ZrPO}_{4}\left(\mathrm{C}_{10} \mathrm{H}_{14} \mathrm{~N}_{2} \mathrm{O}_{8}\right)_{0.5}\left(\mathrm{CH}_{3}\right)_{2} \mathrm{SO}\right)$.

Figure 4 shows the XRD pattern of $\lambda-\mathrm{ZrPH}_{2} \mathrm{Y}$. It allows the calculation of an interlayer distance of about $1.64 \mathrm{~nm}$, much larger than that of the pristine $\lambda-\mathrm{ZrP}$ $(1.02 \mathrm{~nm}$; figure 2). Moreover, no reflection peaks correspond to Cl-phase $(1.02 \mathrm{~nm})$ or $\mathrm{OH}$-phase $(0.98 \mathrm{~nm})$ can be observed, ${ }^{2,8}$ which means that $\lambda-\mathrm{ZrPH}_{2} \mathrm{Y}$ is obtained as a pure solid phase.

Figure 5 shows the structure of the most stable conformer of EDTA as calculated by MM+ molecular mechanics method. It shows also a plausible arrangement of the doubly deprotonated molecules of EDTA within $\lambda-\mathrm{ZrP}$ complying with the measured interlayer distance of $\lambda-\mathrm{ZrPH}_{2} \mathrm{Y}$.

Figure 6 shows the FT-IR spectrum of the pristine $\lambda$ $\mathrm{ZrP}^{7}$ The bands at low-frequency region are ascribed to $\mathrm{PO}_{4}$ vibration bands. The bands around $3000 \mathrm{~cm}^{-1}$ are assigned to $\mathrm{C}-\mathrm{H}$ symmetric and asymmetric stretching vibrations of dmso methyl groups and those at 1420 and $1320 \mathrm{~cm}^{-1}$ are attributed to symmetric and asymmetric bending vibrations of the same groups.

The FT-IR spectrum of $\lambda-\mathrm{ZrPH}_{2} \mathrm{Y}$ (figure 6) is mostly a composite of those of $\lambda-\mathrm{ZrP}$ and free EDTA. The band at $1676 \mathrm{~cm}^{-1}(\mathrm{COOH})$ in FT-IR spectrum of EDTA is

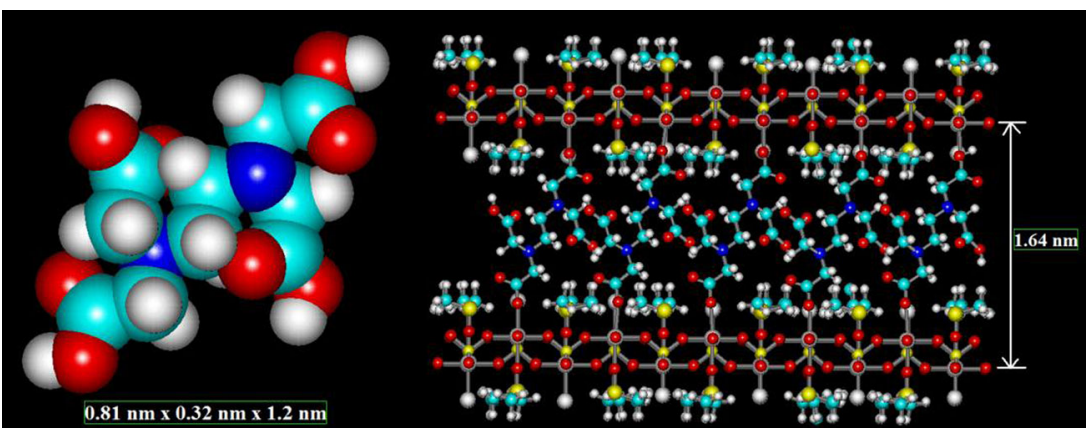

Figure 5. Calculated structures: Predicted most stable conformation of $\mathrm{H}_{4} \mathrm{Y}$ (HyperChem, MM+) (left). Possible arrangement of $\mathrm{H}_{4} \mathrm{Y}$ molecules in $\lambda-\mathrm{ZrP}$ complying with the observed interlayer distance of $\lambda-\mathrm{ZrPH}_{2} \mathrm{Y}$ (right). 

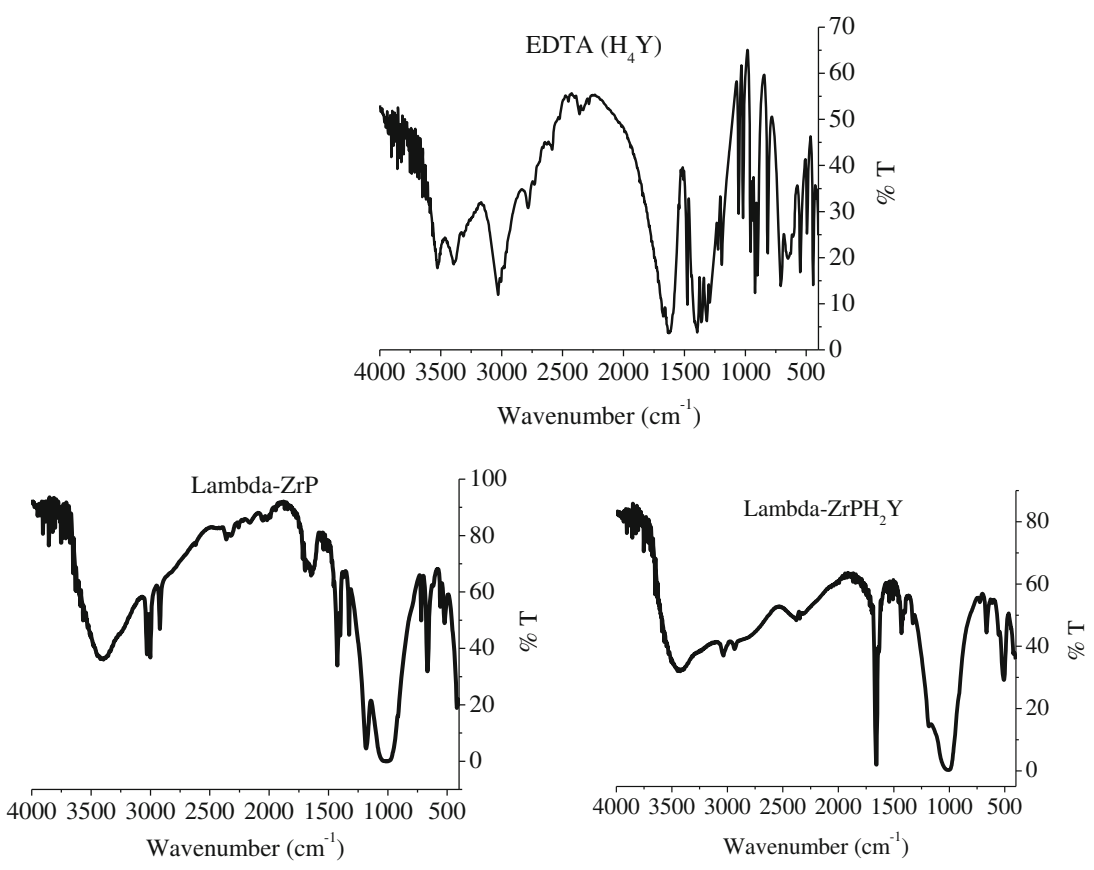

Figure 6. FT-IR spectra of the free EDTA $\left(\mathrm{H}_{4} \mathrm{Y}\right), \lambda-\mathrm{ZrP}$ and $\lambda-\mathrm{ZrPH}_{2} \mathrm{Y}$.

shifted to be at lower frequencies $\left(1654 \mathrm{~cm}^{-1}\right)$ in that of $\lambda-\mathrm{ZrPH}_{2} \mathrm{Y}$. The very broad band within the region $2500-350 \mathrm{~cm}^{-1}$ belongs to the $\mathrm{OH}$ stretching of the free $\mathrm{COOH}$ groups of EDTA (two groups per moiety) (figure 5) inside the interlayer region of $\lambda-\mathrm{ZrPH}_{2} \mathrm{Y}$.

\subsection{Applications}

One measure of water quality is 'hardness' which is defined by the amount of $\mathrm{Mg}^{2+}$ and $\mathrm{Ca}^{2+}$ ions in a given amount of water.

It is worth mentioning that the study is conducted at Gaza strip in which the natural water suffers from very high degree of hardness. The concentration of $\mathrm{Ca}^{2+}$ present in the tap water has $1088 \mathrm{ppm}$. Synthesis and design of materials towards efficiently entrapping $\mathrm{Ca}^{2+}$ are of great industrial importance.

Actually, the metal ion uptake capacity for $\mathrm{Ca}^{2+}$ is determined by shaking the pristine $\lambda-\mathrm{ZrP}$ and its new polyaminocarboxylic acid functionalized derivative $(\lambda$ $\left.\mathrm{ZrPH}_{2} \mathrm{Y}\right)$ with buffered tap water (T.W.) at $\mathrm{pH} 10\left(\mathrm{NH}_{3}-\right.$ $\mathrm{NH}_{4} \mathrm{Cl}$ ). At this $\mathrm{pH}$, the protonation reactions of the exchanged $\mathrm{H}_{4} \mathrm{Y}$ inside the solid matrix are not expected to compete with the complexation reaction with $\mathrm{Ca}^{2+}$. Therefore, the strongest complex is formed. ${ }^{9}$

With regard to the shaking time dependence of $\mathrm{Ca}^{2+}$ uptake from tap water, two sets of measurements using flame photometer are performed. One set of measurements is performed after treating several T.W. samples $\left(\mathrm{V}_{\text {sample }}=12.5 \mathrm{~mL}\right)$ with the same amount of $\lambda-\mathrm{ZrP}$ $(250 \mathrm{mg})$ at different time intervals $(0.5-2 \mathrm{~h})$. A second set of measurements is performed after treating another set of T.W. samples $\left(\mathrm{V}_{\text {sample }}=12.5 \mathrm{~mL}\right)$ with the same amount of $\lambda-\mathrm{ZrPH}_{2} \mathrm{Y}(250 \mathrm{mg})$ at the same time intervals mentioned above. The results are given in figure 7.

As an important point, all the tap water samples are taken from the same $4 \mathrm{~L}$ polyethylene bottle, which is filled with tap water to perform the above mentioned analyses.

It is clearly seen from the kinetics curves (figure 7) that with both $\lambda-\mathrm{ZrP}$ and $\lambda-\mathrm{ZrPH}_{2} \mathrm{Y}$, the metal uptake reaches the equilibrium after ca. 24 hours, where the maximum $\mathrm{Ca}^{2+}$ uptake is obtained (32.0 and $40.4 \mathrm{mg}$ $\mathrm{Ca}^{2+} / \mathrm{g} \lambda$-solid, respectively). These uptake values correspond to ca. 0.8 and $1.0 \mathrm{mmol} \mathrm{Ca}{ }^{2+} / \mathrm{g} \lambda$-solid and $\%$ $\mathrm{Ca}^{2+}$ uptake of 60 and $74 \%$ (figure $7 \mathrm{~b}$ ), respectively. Also, figure 7 shows that the $\mathrm{Ca}^{2+}$ uptake takes place faster in case of $\lambda-\mathrm{ZrPH}_{2} \mathrm{Y}$.

As an important point to be mentioned, the amount of $\mathrm{Ca}$ (II) uptaken by $\lambda-\mathrm{ZrPH}_{2} \mathrm{Y}$ (ca. $1 \mathrm{mmol}$ ) is very near to the number of mmol of EDTA anion present in $1 \mathrm{~g}$ of the solid $(1.22 \mathrm{mmol})$.

The unexpected $\mathrm{Ca}^{2+}$ uptake capacity of the pristine $\lambda-\mathrm{ZrP}$ could be attributed to its high affinity for $\mathrm{OH}^{-}$in basic aqueous solutions. ${ }^{6,8}$ In this respect, it is essential to mention that the $\mathrm{Cl} / \mathrm{OH}^{-}$and $\mathrm{dmso} / \mathrm{H}_{2} \mathrm{O}$ exchange reactions proceed very fast and the $\mathrm{OHH}_{2} \mathrm{O}$ phase, $\mathrm{ZrPO}_{4} \mathrm{OHH}_{2} \mathrm{O} .\left(\mathrm{H}_{2} \mathrm{O}\right)_{3}$, is obtained. ${ }^{6,8}$ Therefore, if $\lambda-\mathrm{ZrP}$ is contacted with the buffered T.W. samples $(\mathrm{pH}=10)$, then the above mentioned exchange reactions are expected to occur and be followed by 

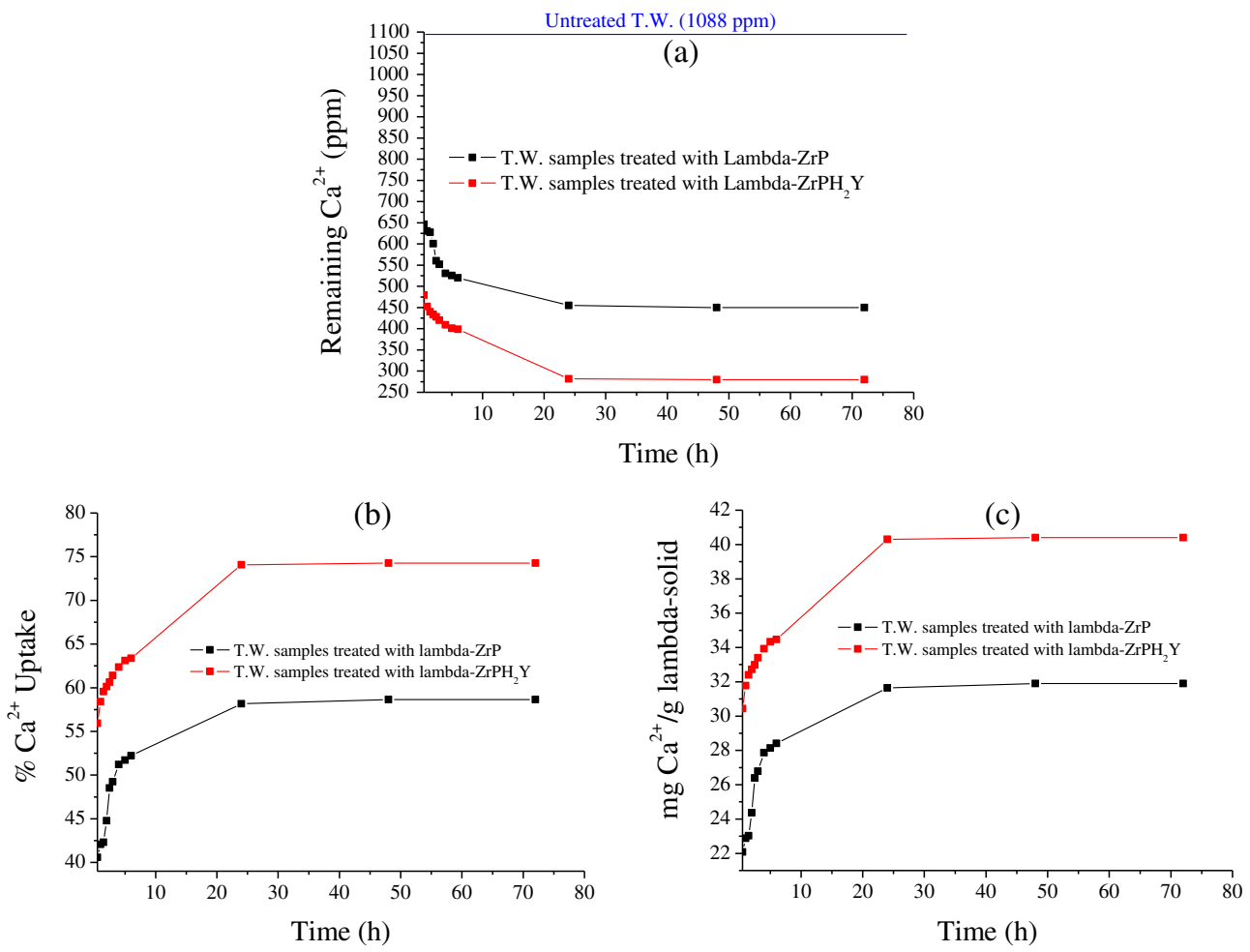

Figure 7. kinetic curves of $\mathrm{Ca}^{2+}$ uptake from tap water samples (T.W.). a) The remaining concentration of $\mathrm{Ca}^{2+}$ (ppm) in TW samples after treatment with $\lambda$-solids. b) $\% \mathrm{Ca}^{2+}$ uptake by $\lambda-\mathrm{ZrP}$ and $\lambda-\mathrm{ZrPH}_{2} \mathrm{Y}$. c) $\mathrm{Ca}^{2+}$ uptake capacities of $\lambda-\mathrm{ZrP}$ and $\lambda-\mathrm{ZrPH}_{2} \mathrm{Y}\left(\mathrm{mg} \mathrm{g}^{-1}\right)$.

another one between the $\mathrm{OHH}_{2} \mathrm{O}$-phase and $\mathrm{Ca}^{2+}$ ions in T.W. samples. The following scheme summarizes the three exchange reactions mentioned above.

Cldmso-phase $+\mathrm{H}_{2} \mathrm{O} \rightarrow \mathrm{OHH}_{2} \mathrm{O}$-phase

$\mathrm{OHH}_{2} \mathrm{O}$-phase $+1 / 2 \mathrm{Ca}^{2+} \rightarrow \mathrm{O}(\mathrm{Ca})_{1 / 2} \mathrm{H}_{2} \mathrm{O}$-phase $+\mathrm{H}^{+}$

In order to be more certain with regard to the above mentioned $\mathrm{Ca}^{2+} / \mathrm{H}^{+}$exchange, the separated solid, after a contact time of $24 \mathrm{~h}$ between $\lambda$-ZrP and buffered tap water, was re-suspended in $12.5 \mathrm{~mL}$ of deionized water. The mixture was then agitated and its $\mathrm{pH}$ adjusted at 5 over a time interval of $3 \mathrm{~h}$ by dropwise addition of $0.1 \mathrm{M} \mathrm{HCl}$. Finally, the supernatant was separated and analyzed by flame photometer. This analysis shows that an amount of $\mathrm{Ca}^{2+}(7.0 \mathrm{mg})$ equivalent to ca. $86 \%$ of the total amount of calcium uptaken by this solid (ca. $8.2 \mathrm{mg}$ ) is released. This chemical test ensures that $\mathrm{Ca}^{2+} / \mathrm{H}^{+}$exchange is the key step in the uptake mechanism through which $\mathrm{OHH}_{2} \mathrm{O}$-phase extracts $\mathrm{Ca}^{2+}$ from tap water.

Figure 8 compares the FT-IR spectra of the separated solid products after a contact time of $2,4,6,24 \mathrm{~h}$ between the pristine $\lambda$-ZrP and buffered T.W. samples. They provide strong evidence that the hydroxyl derivative $\left(\lambda-\mathrm{ZrPO}_{4} \mathrm{OHH}_{2} \mathrm{O} .\left(\mathrm{H}_{2} \mathrm{O}\right)_{\mathrm{x}}\right)$ is formed during the course of the uptake process, where the symmetric and asymmetric stretching $\left(2920,3000\right.$ and $\left.3020 \mathrm{~cm}^{-1}\right)$ and bending bands $\left(1420\right.$ and $\left.1320 \mathrm{~cm}^{-1}\right)$ of dmso disappear increasingly as the uptake duration time is gradually increased. It is obvious that a contact time of ca. $24 \mathrm{~h}$ is necessary to force this phase transformation to be completed. Because of that, no further change in the uptake capacity is observed over interval times longer than $24 \mathrm{~h}$ (figure 7).

In case of $\lambda-\mathrm{ZrPH}_{2} \mathrm{Y}$, the very high $\mathrm{Ca}^{2+}$ uptake capacity could be attributed to three main factors: (1) increasing the hydrophilicity as a result of the dmso/ $\mathrm{H}_{2} \mathrm{O}$ exchange, so the diffusion of $\mathrm{Ca}^{2+}$ into the interlayer gallery can be facilitated, (2) its higher interlayer gallery in comparison to $\lambda-\operatorname{ZrP}(1.64$ and $1.02 \mathrm{~nm}$, respectively), (3) the presence of the exchanged EDTA inside its solid matrix, therefore EDTA-Ca ${ }^{2+}$ complex is expected to be formed.

Figure 9 compares the FT-IR spectra of the separated solid products after a contact time of 2, 4, 6, 24 h between $\lambda-\mathrm{ZrPH}_{2} \mathrm{Y}$ and buffered T.W. samples. As in the case $\lambda-\mathrm{ZrP}$, dmso/ $\mathrm{H}_{2} \mathrm{O}$ exchange is completed at $24 \mathrm{~h}$ and no further change in the uptake capacity is observed over longer interval times (figure 7).

In conclusion, the obtained results show that $\lambda-\mathrm{ZrP}$ and $\lambda-\mathrm{ZrPH}_{2} \mathrm{Y}$ are highly efficient materials for the 

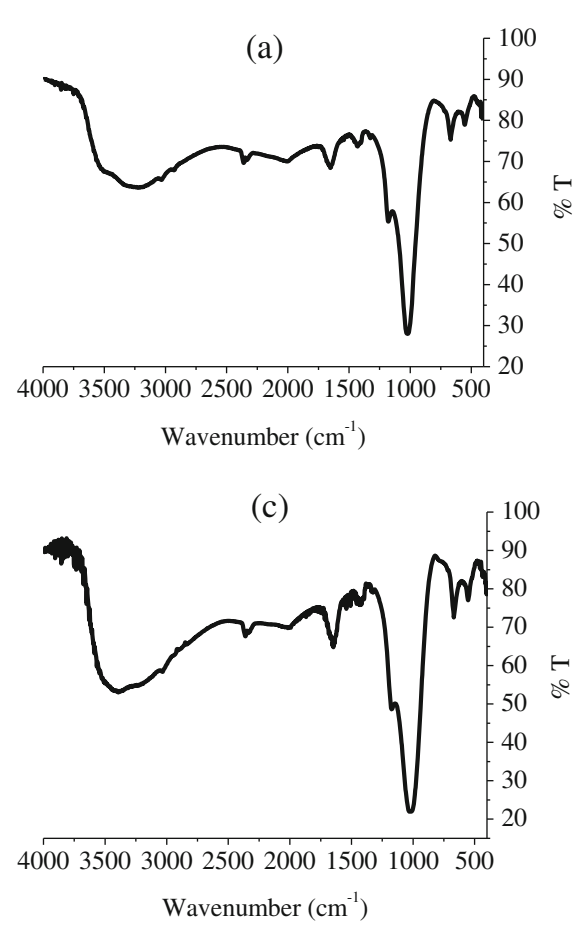

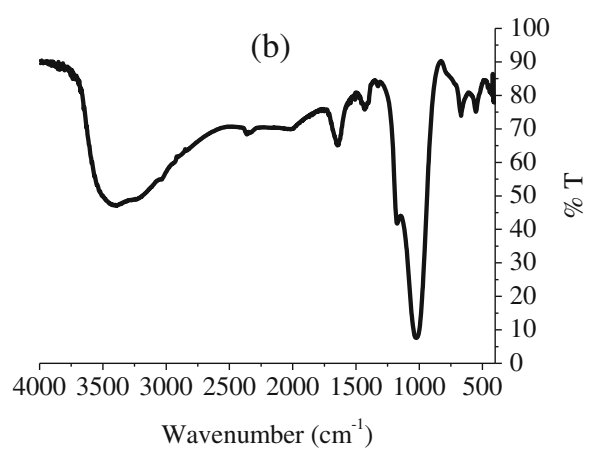

(d)

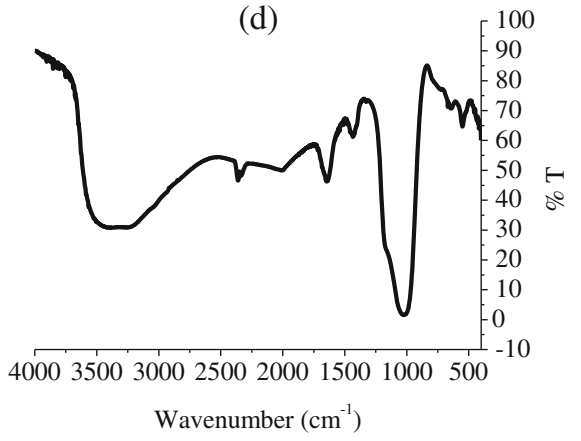

Figure 8. FT-IR spectra of the separated solids after a contact time of (a) $2 \mathrm{~h}$, (b) $4 \mathrm{~h}$, (c) $6 \mathrm{~h}$ and (d) $24 \mathrm{~h}$ between the pristine $\lambda-\mathrm{ZrP}$ and buffered T.W. samples.

removal of $\mathrm{Ca}^{2+}$ from hard water. Moreover, equilibrium is established during a course of time of $24 \mathrm{~h}$, where the maximum uptake is recorded (32.0 and $40.4 \mathrm{mg} \mathrm{Ca}^{2+} / \mathrm{g} \lambda$-solid, respectively).

\subsection{Related work}

The inorganic supports based on silica-gel that carry carboxylic groups has shown a great importance for
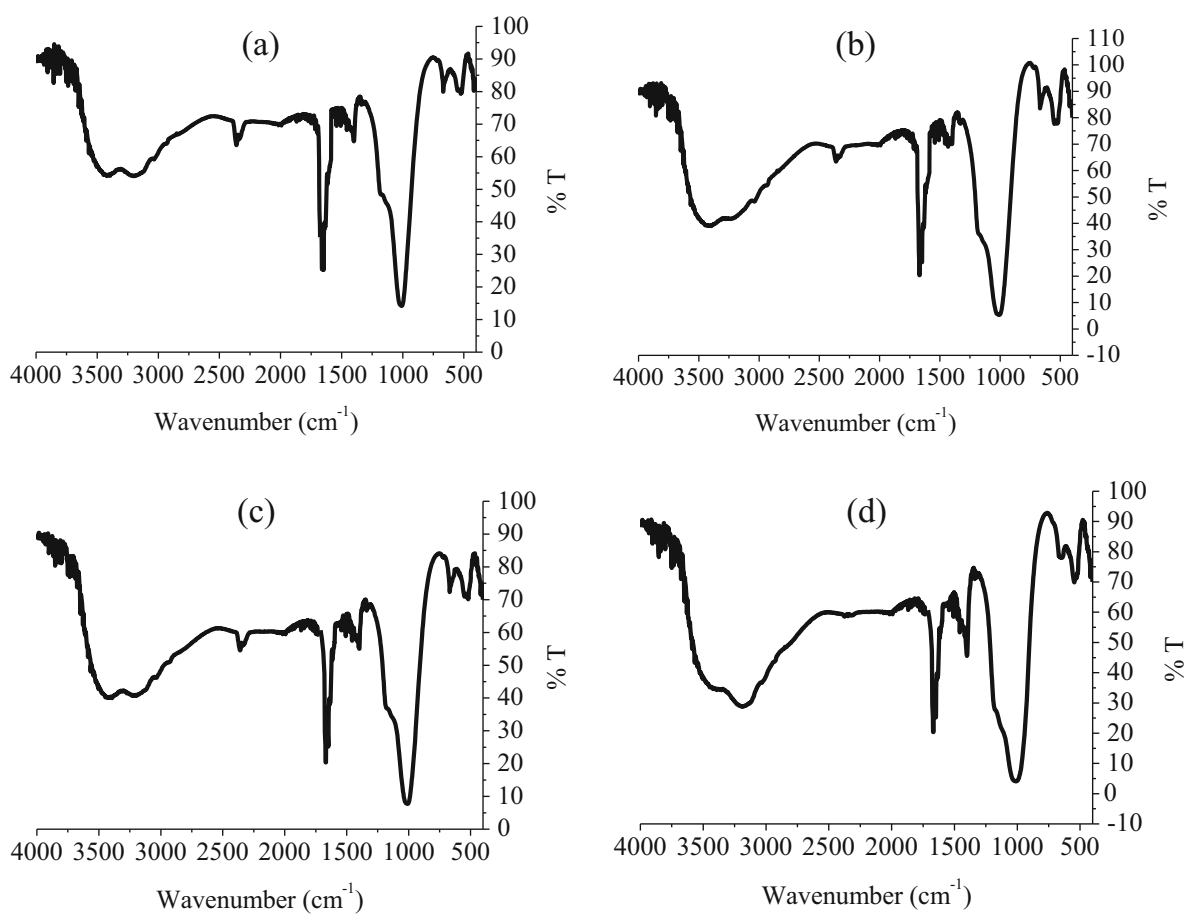

Figure 9. FT-IR spectra of the separated solids after a contact time of (a) $2 \mathrm{~h}$, (b) $4 \mathrm{~h}$, (c) $6 \mathrm{~h}$ and (d) $24 \mathrm{~h}$ between $\lambda-\mathrm{ZrPH}_{2} \mathrm{Y}$ and buffered T.W. samples. 
metal ions extraction. ${ }^{10-13}$ This research sheds light on $\mathrm{Ca}^{2+}$ uptake capacity of two porous layered materials: the pristine $\lambda-\mathrm{ZrP}$ and its polyaminocarboxylic acid derivative with ethylenediaminetetraacetic acid $\left(\lambda-\mathrm{ZrPH}_{2} \mathrm{Y}\right)$.

\section{Conclusion}

Elemental and thermogravimetric analyses, X-ray diffractometry, FT-IR spectroscopy and molecular modelling show that EDTA is successfully incorporated inside the interlayer gallery of $\lambda$-ZrP by means of topotactic carboxylate/Cl ligand exchange reaction. $\lambda-\mathrm{ZrP}$ and its new polyaminocarboxylic acid derivative $(\lambda-\mathrm{ZrPY})$ exhibit high potential for extraction metal ions $\left(\mathrm{Ca}^{2+}\right)$ from hard water. Finally, it is expected that this study contributes to the related empirical studies as it attempts to fill the critical gap in the existing literature.

\section{Acknowledgement}

The author is grateful to the Association of Arab Universities for financial support.

\section{References}

1. Alhendawi H 2014 J. Chem. Sci. 126(4) 975

2. Vivani R, Masci S and Alberti G 2004 Inorg. Chem. 43 368

3. Alberti G 1998 Sc. Tech. 80607

4. Alberti G, Casciola M, Costantino U and Vivani R 1996 Adv. Mater. 8291

5. Poojary D M, Zhang B and Clearfield A 1994 J. Chem. Soc. Dalton Trans. 2453

6. Alberti G, Bartocci M, Santarelli M and Vivani R 1997 Inorg. Chem. 363574

7. Caneschi A, Gatteschi D, Sangregorio C, Vaz M G F, Costantino U, Nocchetti M and Vivani R 2002 Inorg. Chim. Acta. 338127

8. Alberti G, Masci S and Vivani R 2002 Inorg. Chem. 41 1913

9. Skoog D A, West D M, Holler F J and Crouch S R 2004 In Fundamentals of Analytical Chemistry $8^{\text {th }}$ edition (Canada: Thomson Learning) Chap. 17

10. El-Nasser A A and Parish R V 1999 J. Chem. Soc., Dalton Trans. 193463

11. El-Kurd H M, El-Nahhal I M and El-Ashgar N M 2005 Phosphorus, Sulfur Silicon Relat. Elem. 180(7) 1657

12. El-Ashgara N M, El-Nahhal I M, Chehimi M M, Babonneau F and Livage J 2009 Intern. J. Environ. Anal. Chem. 89(14) 1057

13. El-Ashgara N M, El-Nahhal I M, Chehimi M M, Babonneau F and Livage J 2009 J. Dispersion Sci. Technol.30(5) 684 